\title{
Vuelta a una ontología trinitaria. Persona y Trinidad en Ser finito y ser eterno de Edith Stein
}

\author{
AgUSTINA MARÍA LOMBARDI* \\ ANCBA/CONICET-Universidad Austral (Argentina) \\ alombardi@austral.edu.ar
}

\begin{abstract}
Resumen
Según el diagnóstico sobre la academia contemporánea del pensador italiano Piero Coda, la teología, disciplina escindida de la filosofa desde la modernidad, se ha reducido a una mera apologética de la fe. En este marco, la Trinidad se vacía de contenido ontológico, dejando de ser principio de interpretación de la realidad. En el presente artículo analizaré las consecuencias antropológicas que posee el hecho de que la creación, específicamente del hombre, sea imago Trinitatis en el pensamiento de Edith Stein. En la primera sección, presentaré brevemente cómo Stein aborda el misterio y las relaciones intra-trinitarias utilizando las imágenes del amor y de la vida. Luego, presentaré brevemente el desarrollo de la noción de persona y como ésta es resignificada a la luz del dogma trinitario para explicar en qué sentido Dios es persona. En la segunda sección, presentaré cómo se da la imagen del Dios Trino en la creación. Este será el primer paso, dado que para Stein el discurso cosmológico es solo la antesala del discurso antropológico. Finalmente, analizaré cómo se da la imagen del Dios trinitario en la persona humana y por ende cómo esta noción es resignificada y enriquecida.
\end{abstract}

Palabras clave: Edith Stein, ontología trinitaria, Trinidad, persona, imago Trinitatis.

\section{Back to a trinitarian ontology. Person and Trinity in Edith Stein's Finite and Eternal Being}

\begin{abstract}
According to the diagnosis on the contemporary academy of the Italian thinker Piero Coda, theology, having been cut off from philosophy since modernity, has been reduced to mere apologetics. Within this framework, the doctrine of the Trinity is emptied of any ontological content, ceasing to be a principle of interpretation of reality. In this article I will analyse the anthropological consequences of the fact that creation, specifically of man, is imago Trinitatis in the thought of Edith Stein. In the first section, I will briefly present how Stein approaches mystery and intra-Trinitarian relationships using the images of love and life. Then, I will offer a quick description of the development of the notion of person and how it is re-signified in light of the Trinitarian dogma as to explain in what sense God is a person. In the second section, I will present how the image of the Triune God appears in Creation, a first step in cosmological discourse that will lead, for Stein, to the anthropological discourse. Finally, I will analyse how the image of the Trinitarian God is present to the human person and therefore how this notion is re-signified and enriched.
\end{abstract}

Keywords: Edith Stein, Trinitarian ontology, Trinity, person, imago Trinitatis.

* Profesora de Filosofía (UCA, Argentina), Master of Studies in Modern Theology (Oxford, Reino Unido); Becaria Doctoral (Academia Nacional de Ciencias de Buenos Aires/CONICET, Argentina). Profesora en la Facultad de Ciencias Biomédicas de la Universidad Austral, Argentina.

Recibido: 5/Abril/2018 - Aceptado: 6/Julio/2018 


\section{INTRODUCCIÓN}

La noción de persona es esencial en la teología cristiana, sobre todo en el desarrollo de las doctrinas cristológicas y trinitarias, que han jugado un rol central en el desarrollo de su significado. Como sostiene el teólogo Hans Urs von Balthasar: "the word person in the sense of a human being... receives its special dignity in history when it is illuminated by the unique theological meaning" (1986: 18). Pero es sobre todo la noción de 'Trinidad' la que ilumina no solo el sentido de la persona sino del ser mismo. En efecto, como sostiene el teólogo italiano Piero Coda: "el concepto de Trinidad ha propiciado en la época patrística, con respecto a Dios, al hombre, y al cosmos, la resignificación y en algunos casos la creación ex novo de conceptos decisivos, en el entramundo interpretativo y performativo del ser" (2018: 23). Dentro de estos términos creados ex novo se halla el concepto de persona, que si bien ya era usado en el léxico griego, adquiere una resignificación completamente novedosa a la luz del desarrollo del dogma trinitario.

Ahora bien, según Coda, frente al nihilismo reinante de nuestros tiempos, la teología, que ha quedado fuera del debate contemporáneo y escindida de la filosofa desde la modernidad, se ha reducido a una mera apologética de la fe, encerrada en el dogma. En este marco, la Trinidad se vacía de contenido ontológico, pierde su carácter performativo intrínseco y por ende queda sin consecuencias antropológicas relevantes. En suma, la doctrina trinitaria deja de ser principio de interpretación de la realidad:

La gran teología trinitaria de esos siglos no ha sido plenamente capaz de marcar, en la raíz y en todas sus expresiones, la antropología y, en ultima instancia, el ejercicio del pensamiento (...) El concepto de la Trinidad ha quedado confinado dentro del perímetro de categorías y de una forma del pensamiento todavía profundamente marcadas por la pre-comprensión metafísica griega (...) la doctrina trinitaria no es más -como para los Padres y el Medioevo- principio de iluminación y transformación de la realidad. (Coda, 2018: 24, 26-27)

Mi objetivo en este artículo es presentar la noción de persona a la luz de la ontología trinitaria tal como la desarrolla la fenomenóloga y teóloga Edith Stein en su obra Ser finito y ser eterno. Stein dedica toda su vida a pensar y escribir acerca de la naturaleza de la persona humana, uno de los problemas que más la aqueja. Comenzando con su tesis doctoral Sobre el problema de la empatía (1970), donde analiza la constitución de la persona humana a través de la empatía, y pasando por el curso antropológico impartido en el invierno de 1932/33 en el Deutsches Institut für wissenschaftliche Pädagogik en 
Münster, donde desarrolla por primera vez de modo sistemático su visión de la persona humana luego de su conversión al catolicismo. Sin embargo, es en Ser finito y ser eterno donde Stein profundiza, resignifica, y da el fundamento último del ser personal al analizar la imagen de la Trinidad en la persona humana.

La relevancia del pensamiento de Edith Stein se hace evidente frente a la noche oscura en la que se han sumergido la filosofía y la teología. En efecto, en su libro Para una ontología trinitaria. Si la forma es relación, Coda sostiene que surge la necesidad y el reflorecimiento de nuevas formas de pensamiento, entre ellas una renovación de la teología mística (en clave trinitaria) con autores como Von Baltashar, Karl Barth, Simone Weil, entre otros. Ante este panorama, el pensamiento de Edith Stein se presenta como estimulante y capaz de ser tomado como punto de partida del cual se abren nuevas direcciones para la comprensión del Dios personal trinitario, su obra creadora y, más específicamente, el ser personal humano. En efecto, para Stein, al igual que para Balthasar y Coda, la noción de persona no sólo es acuñada en el marco del dogma trinitario, sino que es a su vez enriquecida y resignificada, trayendo nuevos niveles de comprensión del ser finito personal. En consecuencia, para Stein una visión antropológica nunca será completa si no cuenta con la mirada teológica y no tiene en cuenta la relación del hombre con Dios: "la antropología filosófica, así pues, necesita el complemento de la antropología teológica" (2007a: 30). Esto se debe a que el hombre solo alcanza la dignidad del ser personal por haber sido creado a imagen de Dios, de hecho, a imagen del Dios Trino. El hombre es, para Stein, imago Trinitatis. Es a partir de esta imago Trinitatis que Stein incorpora la noción de relación como un elemento constitutivo de la persona, cuya realidad solo puede ser concebida como abierta y dirigida al otro.

En el presente artículo, por lo tanto, analizaré las consecuencias antropológicas que posee el hecho de que la creación, y específicamente el hombre, hayan sido creados a imago Trinitatis en el pensamiento de Edith Stein. En la primera sección, presentaré brevemente cómo Stein aborda el misterio y las relaciones intra-trinitarias utilizando las imágenes del amor y de la vida. Luego, presentaré el desarrollo de la noción de persona y como ésta es resignificada a la luz del dogma trinitario para explicar en qué sentido Dios es persona. En la segunda sección, analizaré cómo se da la imagen del Dios Trino en la creación. Este será el primer paso, dado que para Stein el discurso cosmológico es solo la antesala del discurso antropológico. Finalmente, presentaré cómo se da la imagen del Dios trinitario en la persona humana y por ende cómo esta noción es resignificada y enriquecida. 
1. UN DIOS TRINO Y PERSONAL: CLAVE INTERPRETATIVA DEL SER REAL FINITO

El Dios cristiano se ha revelado como un Dios Trino. Lejos de quedarse con el solo dato revelado y con la doctrina que se sigue de él, Edith Stein considera que mediante la comprensión del misterio trinitario se nos revela también algo esencial del ser del hombre y del resto de las creaturas en general. Esto se debe, dice, a que Dios es el arquetipo de todas las cosas creadas, y que si Dios es un Dios Trino, todos los seres finitos deben estar creados a imagen del Dios trinitario. El dogma trinitario se vuelve, en el pensamiento de Stein, clave para interpretar la realidad. Sumado a esto, el Dios cristiano se nos revela, también, como un ser personal. Comprender en qué sentido Dios es persona, considera Stein, nos ayudará a comprender el ser personal humano. En la presente sección me centraré en presentar brevemente cómo aborda Stein el misterio trinitario a través de dos vías: el amor y la vida, que serán la base de su ontología trinitaria y la clave interpretativa de la relación de Dios con su obra creadora y con el hombre en cuanto ser personal. Luego pasaré a analizar el ser personal divino. Para este análisis, presentaré primero brevemente el origen de la palabra 'persona' en el teatro clásico griego y la resignificación que adquirió a la luz del dogma trinitario. En segundo lugar, explicaré por qué puede decirse que Dios es persona en sentido pleno.

Dios es un Dios Trino. Esto quiere decir que en Dios hay tres personas distintas, pero que la esencia divina es la misma para las tres personas, ya que las tres son totalmente iguales en cuanto son un único Dios: "una unidad perfecta del nosotros que ninguna comunidad de personas finitas podría alcanzar" (Stein, 2007b: 947). La diferenciación de las personas, por tanto, está dada por la relación entre ellas. Stein aborda el misterio de las relaciones intra-trinitarias por dos vías: el amor y la vida. En primer lugar, con San Agustín, reconoce al amor como el locus trinitario (De Trinitate, Libro VIII, capítulos 7-10; Coda, 2018: 74-83). Efectivamente, la vida intra-trinitaria es una entrega amorosa entre personas, una entrega mutua de un yo a un tú, que juntos constituyen una unidad superior a la del yo, una unidad de amor: "Es entrega de sí mismo a un tú, y ser uno en su perfección en base a la mutua entrega de sí. Puesto que Dios es el amor, el ser divino debe ser el ser-uno de una pluralidad de personas y su nombre 'yo soy' equivale a 'yo me doy enteramente a un tú', y por lo tanto también como un 'nosotros somos"' (Stein, 2007b: 947). Así, se puede afirmar que la vida íntima del Dios Trino es el amor recíproco, la entrega mutua y eterna de las personas divinas entre sí: "lo que se entrega recíprocamente es una única, eterna e infinita esencia que abraza perfectamente a cada una de ellas y a todas juntas. El Padre lo ofrece -desde toda la eternidad-al 
Hijo, en cuanto que lo engendra, y mientras el Padre y el Hijo se dan el uno al otro, el Espíritu Santo procede de ellos, como su amor recíproco y entrega" (Stein, 2007b: 948). La segunda vía que utiliza para adentrarse en el misterio trinitario es el de la vida. Stein comprende la vida como aquel movimiento interno, que brota desde dentro, desde lo más íntimo del individuo según su misma esencia, y que a su vez se vuelca al exterior saliendo fuera de $\mathrm{s}^{1}$. Dios es vida por excelencia, y esto quiere decir que "es un movimiento que se produce a partir de la interioridad propia desde dentro, en definitiva, un ser generador" (Stein, 2007b: 948). Ahora bien, este movimiento interno generador puede ser, por un lado, un movimiento hacia fuera como el que ocurre en el acto creador del ser finito, pero por el otro se trata del movimiento propio de la vida intra-trinitaria:

[...] un movimiento eterno en sí mismo, de un eterno sacar de sí partiendo del fondo del ser propio infinito, como la entrega-regalo del yo eterno a un tú eterno, un eterno recibirse y darse correspondientes. Y puesto que el seruno que brota eternamente en este dar y recibir produce una vez más en común de sí lo que es dado y lo que es recibido -porque el ser-uno supremo como tal tiene que ser necesariamente fecundo-, el círculo de la vida interior de Dios se cierra, por consiguiente, en la tercera persona que es don, amor y vida. (Stein, 2007b: 948)

Estas dos vías de comprensión del modo en el que se da la relación de las personas divinas entre sí es el que nos permitirá vislumbrar, por un lado, el modo de relacionarse del Creador con las creaturas y, por el otro, la estructura trina intrínseca a la creación en general y a cada ser en particular.

Pasemos ahora a considerar el ser personal divino. No es un dato desconocido que el término griego $\pi \rho o ́ \sigma \omega \pi$ ov originalmente refería a la máscara que los actores griegos utilizaban durante las obras de teatro, y que solo en un momento posterior comenzó a designar al individuo que la utilizaba. Fue recién en el siglo tercero cuando el concepto comenzó a utilizarse en contextos filosóficos y teológicos para intentar abordar y explicar el misterio de la Trinidad dada la connotación que el término había adquirido, designando a alguien con dignidad. Citando a Tomás de Aquino, Edith Stein afirma:

$[\ldots]$ pues, porque en las comedias y tragedias se representaba a personajes

1 Stein desarrolla el tema de la vida más adelante en Ser finito y ser eterno (2007b: 847859), pero también en la La estructura de la persona bumana (2007a), cuando analiza el ser personal humano como un microcosmos en el que se reúnen todos los niveles de ser. Allí, analiza los distintos niveles de vida natural: vegetativa, sensitiva y humana. 
famosos, se impuso el nombre de persona para indicar a alguien con dignidad. [...] Por lo cual algunos definen la persona diciendo que es la bipóstasis distinguida por la propiedad relativa a la dignidad (proprietate distincta ad dignitatem pertinente). Como quiera que subsistir en la naturaleza racional es de la máxima dignidad, todo individuo de naturaleza racional es llamado persona [...]. Pero la dignidad de la naturaleza divina supera toda dignidad. Por eso, en grado sumo a Dios le corresponde el nombre de persona. (2007b: 953$954)^{2}$

Por lo tanto, históricamente 'persona' comenzó a designar a Dios no por su sentido etimológico, sino por lo que el término comenzó a designar: racionalidad (en el sentido de espiritualidad) y perfección. Ser persona es ser soporte de una naturaleza racional, lo que implica ser un ser espiritual.

Ahora bien, independientemente del origen que el término pudiera tener, Stein ahonda en la significación de la noción de persona y profundiza en los motivos por los cuales Dios es persona en el sentido más pleno de la palabra. Esto es así no solo por lo que implica ser persona, que veremos más adelante, sino porque Dios mismo se nos revela en Éxodo 3,14 como persona. En efecto, Stein sostiene que "Yo soy el que soy", lejos de querer significar que Dios se llama a sí mismo ser o ente, debe ser interpretado en línea agustiniana, para la cual la expresión divina no quiere decir otra cosa que Aquel que se llama a sí mismo "Yo soy" es el ser mismo en persona. Así, en Dios, que es el ser suma y plenamente personal, el:

'Yo soy' significa: yo vivo, yo sé, yo quiero, yo amo; todo esto no como una sucesión o una yuxtaposición de 'actos' temporales, sino se trata de algo que es absolutamente uno desde toda la eternidad en la unidad del 'acto' divino único en el que coinciden totalmente todos los significados diferentes de 'acto': ser real, presente vivo, ser acabado, movimiento espiritual, acto libre. (Stein, 2007b: 942-3)

En suma, la plenitud de Dios no quiere decir otra cosa que en Él 'yo', 'ser' y 'vida' forman una única realidad indistinguible.

Pero además, no hay que dejar de lado la definición que da Stein de persona, es decir, un ser espiritual y libre. Un ser espiritual es aquel que por un lado, es inespacial e inmaterial, y por el otro, posee una interioridad y sale fuera de sí. En efecto, Stein desarrolla esta noción con profundidad

2 La cita es de Summa Theologiae, I, 29, 3. Mientras que "hipóstasis" (ن் ó $\sigma \tau \check{\alpha} \sigma 1 \varsigma$ ) significa el portador (supuesto) de accidentes y se aplica a cualquier sustancia (o a Dios en el sentido de subsistens, es decir, en cuanto tiene la capacidad de subsistir por sí mismo), "persona" significa el portador de una naturaleza racional (subsistens en rationali natura). 
en La estructura de la persona bumana, donde sostiene que en cuanto ser espiritual, la persona tiene tanto una apertura interna, es decir, es consciente de sí misma y de su vida, la comprende, como externa, está situado en un mundo penetrado de sentido y volcado intencionalmente hacia él. En cuanto ser libre, la persona está inmersa en un mundo que se encuentra atractivo, pero es capaz de decir 'yo puedo', ya que las cosas no se le imponen. La persona puede elegir libremente entre los bienes que se le aparecen, tiene la responsabilidad de elegir y de hacerse a sí misma, de formarse y configurarse a sí misma. Ser persona, para Stein, es ser un 'yo' y de reconocerse como tal. Cuando dos personas se miran, un yo y otro yo se encuentran frente a frente, pero el otro yo solo se volverá un tú, sostiene, si el encuentro se da desde lo más íntimo de la persona, desde su centro interior.

Siguiendo este breve análisis de lo que implica ser persona, puede entenderse como para Stein Dios es persona en el sentido más pleno. Esto significa que Dios, utilizando terminología de La estructura de la persona bumana, posee una apertura tanto interna como externa. La apertura interna se refleja en el hecho de que Dios está completamente presente a sí mismo de una manera clara y transparente: "se capta a sí mismo espiritualmente o es transparente a sí mismo” (Stein, 2007b: 943). Además, en cuanto espíritu, la apertura externa de Dios se puede apreciar dado que Él sale de sí mismo sin perder su ser, y lo hace en el más alto grado, como afirma Stein sobre la vida amorosa de la Trinidad: “en la entrega de sí total de las personas divinas, en la cual cada una se enajena enteramente de su esencia y, sin embargo, la conserva perfectamente, cada una está enteramente en sí misma y enteramente en las otras, tenemos ante nosotros el espíritu en su realización más pura y perfecta. La divinidad trina es el verdadero "reino del espíritu" (2007b: 957)3. Sumada a la vida intra-trinitaria, la apertura externa se refleja a su vez en la creación. Para Stein, solo una persona puede crear, es decir, dar la existencia libre y amorosamente, estableciendo un orden racional o un sentido:

[...] sólo una persona puede crear, es decir, llamar a la existencia en virtud de su propia voluntad. (...) El orden racional y la conveniencia del mundo remiten igualmente a una persona en cuanto autor: sólo por medio de un ser racional puede ser introducido un orden racional en la obra; sólo una esencia que conoce y quiere puede poner fines y ordenar los medios a los fines. Pero razón y libertad son las características esenciales de la persona. (2007b: 941)

Siguiendo a Agustín, Stein se está refiriendo a la doctrina de las procesiones o relaciones entre las Personas de la Trinidad. 
Stein resume el ser personal de Dios del siguiente modo:

[...] si pertenece al yo como tal el que su vida brote de él y que experimente esta vida como la suya propia, entonces el yo personal debe poder además comprender su vida y configurarla libremente desde sí mismo. Así comprendemos que Dios, quien en su libertad perfecta configura su propia vida y que es enteramente luz (al que no hay nada escondido), debe ser persona en el sentido más elevado. (2007b: 958)

En resumen, Dios es el ser personal en grado sumo ya que por un lado Él es el ser espiritual y libre por excelencia, pero además porque Él mismo se ha revelado con el nombre 'Yo soy'. Es momento, ahora, de considerar cómo Edith Stein entiende que la creación es imagen de un Dios Trinitario.

\section{LA IMAGEN DEL DiOs TRINO EN LA CREACIÓN}

El primer paso antes de ahondar en la comprensión de la naturaleza humana a la luz del Dios personal trinitario, es analizar su obra creadora. Para Edith Stein, entre Dios y sus creaturas está latente una doble inclinación: por un lado un abismo, una distancia infinita entre el ser divino y eterno y el ser finito y creado; por el otro, una auténtica relación a modo de imagen entre Dios y su creación. En efecto, para Stein toda la creación, tanto los seres racionales como los irracionales, ha sido creada a imagen del Dios trinitario. En la presente sección, presentaré de qué modo está presente la huella trinitaria en todas las creaturas, mostrando cómo es que se da la imagen de cada una de las personas divinas en los seres finitos creados.

Así como la vida intra-trinitaria puede interpretarse en claves de amor y vida, puede decirse que el acto creador es un acto de amor puro y eterno de Dios por sus creaturas. ${ }^{4}$ Un acto de amor puro que a su vez es un acto de vida, un movimiento en el que Dios sale de sí para darle la vida a un ser distinto de sí. En efecto, Dios llama a la existencia a los seres finitos que, si bien difieren del ser simplísimo divino en cuanto poseen un ser compuesto, participan del ser pleno en diferentes grados ${ }^{5}$. Todos los seres finitos encuentran en Dios el arquetipo de su ser. Así, toda la creación está

\footnotetext{
4 La relación entre Dios y sus creaturas es una relación de amor, pero de un amor desproporcionado, en el que Dios ama a sus creaturas desde toda la eternidad, pero cuyo amor no puede ser correspondido del mismo modo.

5 Stein analiza esta relación gradual en términos de analogía entis, que desarrolla en 2007b: 934-936 y 944-945. Yo me centraré en la imago Trinitatis.
} 
hecha a imagen del Dios Trinitario. Esta idea, de clara influencia agustiniana, recibe en Stein un nuevo giro. De acuerdo con San Agustín, todos los seres creados llevan en sí mismos y en sus relaciones una huella del Dios Trino que los ha creado. A esta huella la denomina vestigium Trinitatis, que distingue de la imago Trinitatis, que solo se da en los seres racionales creados a imagen de Dios. Dice Coda: "De tal modo es posible y necesario que, conociendo al Creador por medio de sus obras, celebremos la Trinidad, de la cual la creación, en una cierta proporción verdadera, lleva en sí el rastro: el vestigium -palabra mágica que se convertirá en un leimotiv de toda la tradición cristiana" (2018: 63). San Agustín incluso distingue en la misma naturaleza humana rasgos de vestigio y de imagen. En efecto, mientras que el hombre exterior dotado de sentidos corporales posee vestigios del Creador, es el hombre interior dotado de inteligencia el que está hecho a imagen de Dios: "esforcémonos, pues, por indagar, si es posible, en este hombre exterior algún tenue vestigio de la Trinidad, sin que llegue a ser imagen de Dios" (San Agustín, De Trinitate, Libro XI, cap. 1). Edith Stein, que no desconoce esta tradición, se apoya tanto en San Agustín como en Santo Tomás, quien desarrolla esta misma idea en la Summa theologica I, q. 45 , a. $7^{6}$, para afirmar que "encontramos también cierta posibilidad de imagen en lo que Santo Tomás muestra como huella de la Trinidad (...) y hablaremos por tanto simplemente de imagen" (2007b: 951). En definitiva, Stein reconoce que toda la creación, tanto los seres racionales como los irracionales, han sido creados a imagen de la Trinidad, y en este sentido, dice, se aleja de Tomás de Aquino, para quien, como San Agustín, solo los seres racionales han sido creados a imagen de Dios. Esto no quiere decir que para Stein el hombre, que es persona, capaz de vida espiritual cons-

6 En efecto, luego de demostrar que el acto de crear no es algo propio de una sola de las personas divinas, sino que es común a toda la Trinidad de acuerdo con su modo de procedencia, Santo Tomás reconoce, con Agustín, que es posible encontrar una huella o un vestigio de este Dios Trino en todas las creaturas. Distingue, en primer lugar, vestigio de imagen, ya que mientras que el primero representa la causalidad de la causa, del modo que lo hace el humo con respecto al fuego, la imagen representa a la causa según la semejanza de su forma, como lo hace el fuego con el fuego. Mientras que las criaturas noracionales llevan consigo un vestigio de la Trinidad, los seres racionales han sido creados a su imagen. El vestigio trinitario consiste en que "cada criatura subsiste en su ser y tiene la forma con la que está determinada en una especie y tiene alguna relación con algo" (S.Th., I, 45, 7, co.). Es decir, en la medida en la que subsiste, el ser finito es huella de Dios Padre, el mismo ser subsistente; en la media en la que está determinada en una especie, posee una forma, y en este sentido representa y es una huella del Verbo; en la medida en la que tiene una relación con algo posee a su vez un orden y representa al Espíritu Santo en cuanto Amor. Desarrollaremos más profundamente esta idea de acuerdo con el pensamiento de Edith Stein en la presente sección. 
ciente y libre, no "sea una imagen de Dios en un sentido mucho más particular que todas las demás criaturas" (2007b: 1052), sino que prefiere dejar de lado las distinciones terminológicas hechas por Agustín y Tomás y hablar simplemente de una imagen más cercana o más lejana. En suma, para Stein, entre Dios y sus creaturas está latente una doble inclinación, por un lado una distancia infinita ${ }^{7}$, por el otro, una relación a modo de imagen imperfecta o rayo quebrado entre Dios y su creación. Efectivamente, Dios no puede crear un ser diferente al suyo que sea Eterno, Increado e Infinito como Él. Sólo el Verbo, que es 'engendrado, no creado', es imagen perfecta del Padre, ya que comparte su misma naturaleza divina, su esencia, y dado que en Dios esencia y ser no se distinguen, comparte por ende su mismo ser.

Por lo tanto, aunque Dios no puede crear un ser distinto de sí que sea una imagen perfecta de Él, sí crea dejando una huella de su mismo ser trinitario. Para Stein, hay un despliegue trinitario en la creación, toda la realidad se encuentra traspasada por la Trinidad a distintos niveles. En lo que respecta a los seres finitos: 1) En la medida en la que subsisten por sí mismos y son seres independientes, es decir, son oúoí , son una imagen del Padre; 2) en la medida en la que poseen un sentido, una esencia determinada, son una imagen del Logos, la Palabra Eterna de Dios; 3) en la medida en la que despliegan su esencia, tienen una fuerza vital o están vivos, son una imagen del Espíritu Santo. De este modo, todos los seres finitos poseen una estructura trinitaria. Pero incluso si vamos más allá de los seres finitos individuales, podemos ver un símbolo del despliegue trinitario en las distintas agrupaciones de seres. Así, son tres los estados fundamentales de la materia: sólido, líquido y gaseoso; tres los tipos de seres vivos: vegetales, animales y hombres, etc.

Stein analiza el despliegue trinitario en los distintos grados de ser, es decir, en los seres materiales, los seres vivos impersonales, los seres humanos y los ángeles ${ }^{8}$. Con respecto a la imagen en los seres meramente materiales, Stein sostiene que encontramos una doble unidad trinitaria: por

7 En vistas a evitar un panteísmo, Stein sostiene que hay una distancia infinita entre el Creador y sus creaturas, es decir, entre los seres finitos creados que poseen un comienzo temporal y el ser infinito, que es eterno y la causa de la existencia de los seres creados. Esto quiere decir que, mientras que los seres finitos son seres compuestos, de acto y potencia, sustancia y accidentes, ser y esencia, forma y materia; el ser infinito es el ser puro, en cuanto que es acto puro y no posee ningún tipo de composición. Dios es lo absolutamente simple. Siguiendo a Tomás, para Stein no es posible distinguir en Dios esencia y existencia, Dios es la plenitud eternamente presente.

8 En el presente artículo presentaré brevemente la imagen trinitaria en los seres materiales y los seres vivos impersonales para centrarme luego en el hombre, pero dejaré de lado la imagen en los seres angélicos. 
un lado, el ser material es un ser independiente, soporte cósico de su esencia, y en este sentido es una imagen del Padre, pero a su vez posee un sentido que le es otorgado por su esencia, siendo una imagen del Hijo, y despliega su ser en virtud de la fuerza que corresponde a la forma esencial, siendo una imagen del Espíritu Santo. Por el otro, este despliegue del ser es a su vez trinitario: se forma dentro de la forma de la esencia, posee la esencia formada y sale fuera de sí ya sea como relación causal en la naturaleza o como irradiación de su propia esencia en el mundo espiritual.

Dando un paso más en los grados de ser, es decir si analizamos la imagen de la Trinidad en los seres vivos impersonales, podemos ver una cercanía aún mayor, dado que encontramos en los seres vivos las cualidades divinas de la autosuficiencia, autoconservación, entrega de sí y fecundidad. En efecto, la forma del ser vivo es su alma, el centro vital desde donde brota el movimiento interno autoconfigurador, el centro desde donde sale al exterior, recibiendo materias que transforma para que pasen a ser parte de su estructura, y generando seres distintos de sí de la misma especie. Stein afirma:

[...] lo vivo depende más fuertemente de sí mismo que el cuerpo material, porque es algo que comienza en sí mismo; de allí expresa mejor la imagen del Padre. Es una unidad de sentido conclusa en cuanto configuración limitada desde sí misma, es por lo tanto, una imagen más expresiva del Logos. Lleva en sí la fuerza que conduce a un despliegue de la esencia propia y a la generación de nuevas hechuras, en cuanto viva y fecunda constituye una imagen más pronunciada del Espíritu Santo. (2007b: 1014)

Y dentro de lo vivo, el animal, por poseer una estructura anímica interna, es decir, una cierta vida interior, se asemeja aún más a la divinidad. Esta vida interna, sostiene Stein, ya de por sí y aunque no se trate de una vida interna espiritual, lleva la huella de la Trinidad: en cuanto vida independiente es imagen del Padre, en cuanto vida llena de sentido (de contenidos, aunque no sean contenidos comprendidos por un ser personal), es imagen del Hijo, en cuanto vida en sí misma e irradiación de la esencia, es imagen del Espíritu Santo.

Ahora bien, si damos incluso uno paso más en los grados de ser, tanto los ángeles como los seres humanos, dada su naturaleza personal, participan más excelsamente de lo divino. Refiriéndose a los seres humanos, Stein afirma: "una distancia infinita claramente lo distingue del ser divino; y sin embargo, le es más semejante que cualquier otra cosa que forme parte del campo de nuestra experiencia: precisamente porque es un yo, una persona" (2007b: 942). En efecto, como explica Antonio Calcagno: "as crea- 
tures of God we bear the impression or stamp of God in that we are fashions in God's image and likeness. We are persons as God is person" (2007: 94). Estas consideraciones abren el camino para analizar, en la siguiente sección, al Dios trinitario personal como fundamento de nuestro propio ser personal.

\section{LA IMAGEN DE LA TRINIDAD EN EL HOMBRE}

El ser personal de Dios es para Stein fundamento de todos los otros seres personales, en particular de las personas humanas. En efecto, "las criaturas dotadas de razón se asemejan al Creador por lo que las distingue de todas las demás cosas: es decir, por la espiritualidad personal, por eso se puede hablar aquí de una semejanza que no corresponde más que a ellas solas" (Stein, 2007b: 1052). Dada su espiritualidad, es decir, dada su vida consciente y libre, tanto los ángeles como los seres humanos son una imagen de Dios de un modo mucho más genuino que las otras creaturas. Con respecto a la naturaleza humana en particular, Stein construye su argumento a partir de Génesis 1, 27: "Y creó Dios al hombre a su imagen". Dado que este Dios creador es un Dios trino o tri-personal, los hombres expresan la imagen de Dios en al menos dos sentidos: en su naturaleza tripartita y en el principio espiritual humano: en el alma y en el espíritu. En esta sección presentaré cómo se da esta triple imagen y ahondaré en la naturaleza tripartita del hombre, para lo cual me apoyaré también en La estructura de la persona humana.

En primer lugar, los hombres reflejan al Dios Trino en su naturaleza tripartita. Como sostiene M. C. Baseheart: "the person, the I, then, is a three-fold oneness: body-soul-spirit... free acts are the privileged realm of person... For Stein the threefold unity of man -body-soul-spirit- is the image of the Triune God" (1987: 44). En efecto, para Stein, en cuanto que el hombre ha sido creado a imagen del Dios Trino, posee una naturaleza tripartita de cuerpo, alma y espíritu. Esta distinción entre alma y espíritu no implica, sin embargo, la existencia de dos principios espirituales en la naturaleza humana, sino una única alma unificada con facultades distintas. Cuerpo, alma y espíritu reflejan al Hijo, al Padre y al Espíritu Santo respectivamente: a pesar de que la materia es totalmente diferente a Dios, "justamente por su dependencia en la materia, tienen un estrecho lazo de unión con Aquel que descendió a la profundidad del ser terreno, con el Verbo que se hizo carne" (Stein, 2007b: 1056). En cuanto que la materia (cuerpo) es una unidad con la forma (alma) y juntas constituyen una unidad subsistente, hay una semejanza con el Creador. Esta semejanza también se puede apreciar en el hecho de que el alma es "el todo unitario que, en cuanto realidad independiente, es puesta en la existencia. Gracias al 
alma el todo es algo lleno de sentido y vida" (Stein, 2007b: 1036). Finalmente, el espíritu humano es una imagen del Espíritu Santo: "el libre y desinteresado exhalar merece en un sentido particular el nombre de 'espíritu"' (Stein, 2007b: 957). Antes de presentar cómo se da la imagen de la Trinidad en el alma y en el espíritu, ahondaré en la naturaleza tripartita del hombre, comenzando por el cuerpo, el alma y finalmente el espíritu.

El cuerpo, tal como había analizado Edmund Husserl en Ideas II, puede ser abordado como Körper, cuerpo físico, sujeto a las leyes de la física, y Leib, cuerpo vivido. Al analizar el cuerpo en La estructura de la persona bumana, Stein da la siguiente definición: el cuerpo es el "fundamento, expresión e instrumento del alma humana espiritual-personal" (2007a: 106). En primer lugar, en cuanto fundamento, el cuerpo es al mismo tiempo tanto la materia sin la cual el alma humana no puede existir en el mundo natural como la materia que el alma formaliza, y en este sentido es al mismo tiempo una cosa material, un organismo y un ser animado. Con respecto a este primer sentido del cuerpo, Stein afirma que "lo que el individuo humano es y puede llegar a ser no depende únicamente de lo más elevado que haya en él, sino también de todos los niveles de ser más bajos a los que pertenece" (2007a: 106). Esto significa que la vida animada y espiritual depende del cuerpo y de su estado. Cuando el organismo no funciona bien, ya sea por una enfermedad o una malformación, por ejemplo, la vida espiritual no se puede desarrollar sin esfuerzo. En cambio, la corrupción del cuerpo se traslada a complicaciones en el desarrollo de la vida espiritual. En segundo lugar, en cuanto expresión, el cuerpo humano es el modo en el que el espíritu y la vida hablan: "el ser espiritual-anímico y la vida se expresan en el cuerpo, nos hablan a través de él" (Stein, 2007a: 106). Stein ejemplifica esto: el hombre reflexivo, sostiene, refleja esta actitud en su mirada y su frente. Finalmente, en cuanto instrumento, el cuerpo es aquello que el espíritu utiliza para actuar y crear. Por lo tanto, artistas, deportistas, y todos nosotros, necesitamos de nuestros cuerpos de distintos modos. Cada uno de nosotros posee una cierta disposición corporal y habilidades, pero al mismo tiempo puede trabajar para desarrollar o reforzarlas de acuerdo a las necesidades.

Stein presenta al alma espiritual tanto como una forma, ya sea como forma corporis tal como se encuentra en los grados más bajos de ser y como la forma del estrato animal presente en la persona humana, y como espíritu. Esta distinción, enfatiza Stein, no implica la existencia de dos principios espirituales en la naturaleza humana, sino de una misma alma unificada. Analicemos primero el alma humana en tanto forma. Para Stein, los seres humanos en tanto personas están sujetos a una doble formalización (Gestaltung) por parte del alma: una de acuerdo con la estructura esencial del alma y la otra de acuerdo con el libre albedrío de la persona. La primera 
formalización tiene que ver con lo que confiere el modo esencial de ser de un ser personal, es decir, con la intencionalidad y la capacidad de actuar libremente. En este sentido, esta formalización es análoga a la formalización que se encuentra en los grados más bajos de los seres, en la medida en que el alma considerada como una forma interna es lo que configura el propio modo de ser. Esta formalización penetra en todas las capas inferiores de la naturaleza humana, ya que el alma es lo que los une a todos: "en la unidad de la naturaleza humana, todos los 'niveles inferiores' que le pertenecen están bajo la ley del espíritu" (Stein, 2007a: 81). El segundo tipo de formalización es el llevado a cabo por la libre actividad del yo que se auto-determina. Esta formalización es propia de la persona humana como ser libre. De hecho, como ser libre, la persona humana está constantemente formalizando y constituyendo tanto su alma como su propio cuerpo. En cada acto en particular, la persona se está determinando a sí misma: "debido a la unidad de cuerpo y alma, la configuración del alma y del cuerpo ocurre todo en uno" (Stein, 2007a: 69). En este sentido, el alma humana es la forma interna de todo el individuo: de su cuerpo y también de su alma.

Así, la doble formalización del alma se lleva a cabo en los actos particulares de la persona, en sus hábitos y en su cuerpo. El alma formaliza los actos concretos de su vida, y al mismo tiempo informa el carácter de la persona, desarrollando ciertos hábitos. Además, el alma es forma corporis, en lo que Stein también reconoce la presencia de la doble formalización. Así, el alma humana configura el cuerpo en su estructura esencial en tanto cuerpo personal, y al mismo tiempo lo configura en tanto persona libre. En este último sentido, la persona libre puede determinar, con sus actos y hábitos particulares, su propio cuerpo, influyendo en su propio modo de ser permanente. Stein da como ejemplo el alimento y el ejercicio que decidimos darle a nuestro cuerpo. Por ejemplo, el jugador de tenis desarrollará características corporales ciertamente diferentes de las cultivadas por un jugador de fútbol o una bailarina de ballet. Aunque el alma formal interna es lo que le da una unidad al cuerpo, no lo hace exclusivamente. De hecho, el cuerpo, como materia (Körper) y como organismo, también está sujeto a las leyes de la naturaleza física, que escapan a la formalización espiritual.

Con respecto al alma en cuanto espíritu, Sarah Borden explica: "in all her writings at each stage of her career, Stein repeats the claim that each individual has a personal core which is unique to that individual and which characterizes the person and all of her actions" (2003: 36). Este centro único, que da personalidad e individualidad a la persona humana, es el alma espiritual. El término 'espíritu' (Geist), sostiene Stein, posee diferentes significados. Comprende, aunque no puede ser reducido, a ninguno de los 
tres términos latinos intellectus, mens o spiritus. En efecto, el espíritu entendido como intellectus es el espíritu en cuanto conoce o entiende. El intellectus designa la facultad del alma espiritual que se diferencia de la voluntad. El espíritu entendido como mens se refiere al alma en cuanto opuesta a las facultades sensitivas del alma humana. En este sentido, mens designa las facultades superiores del alma espiritual: el intelecto y la voluntad. Finalmente, el término spiritus se refiere a aquello que se opone al cuerpo, no entendido como cuerpo vivido sino como mero Körper. Para Stein, el alma es spiritus mientras que el intelecto y la mente son algo de ella, "aquello en lo que el ser del alma se despliega" (2007a: 127). Esto significa que, mientras que el alma es propiamente espiritual, tanto intellectus como mens designan cierta propiedad o facultad del alma que se está desarrollando constantemente, pero que no refleja lo que el alma espiritual es como un todo.

Además de definir al alma espiritual como aquello que se opone al cuerpo, que es el sentido más difundido de entender el espíritu humano, la originalidad de Stein consiste en su definición del alma espiritual como “"centro del ser', 'núcleo personal' de una naturaleza espiritual-corpórea, de una unidad personal corporal-anímica" (2007a: 126). Por lo tanto, el alma espiritual es nuestro centro más íntimo, donde experimentamos dolor y placer, donde apreciamos los valores y la belleza, desde donde vivimos esos valores y desde donde nos abrimos y encontramos con otras personas. Nuestra alma espiritual es nuestro centro interior, desde donde nos abrimos al mundo que se nos presenta y al otro sin perder nada de nosotros mismos.

Ahora bien, la imagen trinitaria en el hombre se refleja más adecuadamente en su principio espiritual, tanto entendido como alma (forma corporis) como lo específicamente espiritual. En efecto, el alma sola "puede ser considerada en sí misma como una imagen de la Trinidad" (Stein, 2007b: 1036), en cuanto realidad subsistente por sí misma cargada de sentido y de fuerza. Para Stein, el alma como forma corporis posee un movimiento dinámico trino que es una imagen de la Trinidad: el alma configura el cuerpo (Hijo), se configura a sí misma (Padre), y configura al espíritu (Espíritu Santo), elevándolo para que establezca una relación con el Dios personal. Segundo, Stein encuentra una imagen del Dios Trino en el espíritu humano. Como explica Angela Ales Bello: "in the most interior part of the soul the 'spirit' is manifested; it is here in this depth that the human being's similarity to God is revealed" (2008: 157). Luego de analizar el pensamiento de Agustín en De Trinitate y el de Theodor Haecker, Stein muestra cómo la imagen trinitaria en el espíritu se da de tres modos: 1) en un triple despliegue de la vida espiritual ad extra: como conocimiento intelectual, sentimiento y voluntad; 2) en un triple despliegue de la vida espiritual ad intra: como una conciencia interna de uno mismo a través de la memoria, 
una autoconciencia emocional y una afirmación volitiva del propio ser de la persona; y 3) en aquello que unifica el mundo interno y externo: el amor en su triple dimensión, como amor justo de sí mismo, amor al prójimo y amor a Dios. En su análisis sobre el amor, Stein sigue a Agustín, para quien el amor es una entrega y unión recíproca de personas. En su forma más perfecta, el amor es la unión con Dios, y en este sentido, como explica Baseheart: "the being of the person is perfected in the person's relation to God” (1987: 44), o como explica Stein:

[...] la vida divina que se desarrolla en el alma amante de Dios no puede ser otra que la vida trinitaria de la divinidad. Ciertamente es el Dios trinitario a quien se entrega el alma. Ella se entrega a la voluntad de Dios Padre que, por así decirlo, engendra de nuevo a su Hijo en ella. Se une ella al Hijo y querría perderse en Él para que el Padre no viera ya nada en ella más que al Hijo. Su vida se une al Espíritu Santo, se transforma en una efusión divina de amor. (2007b: 1046).

De este modo, el alma humana y Dios se compenetran mutuamente, siempre salvando la distancia infinita que hay entre ambos, pero uniéndose y entregándose libre y mutuamente como dos seres espirituales, y formando así una comunidad.

\section{CONCLUSIÓN}

En el presente artículo me propuse analizar las consecuencias antropológicas que posee el hecho de que la creación, y específicamente el hombre, haya sido creada a imago Trinitatis en el pensamiento de Edith Stein. En la primera sección presenté cómo Stein aborda el misterio y las relaciones intra-trinitarias utilizando las imágenes del amor y de la vida. Efectivamente, la vida intra-trinitaria es una entrega amorosa entre personas, una entrega mutua de un yo a un tú, que juntos constituyen una unidad superior a la del yo, una unidad de amor. Pero las relaciones trinitarias pueden entenderse también como un movimiento vital, un movimiento que se produce a partir de la infinita interioridad divina, un eterno sacar de sí sin perderse, un eterno recibirse y darse correspondientes. Este movimiento propio de la vida intra-trinitaria, también se vuelca hacia el exterior en el acto amoroso de la creación, una creación que solo puede ser fruto de un Dios que es y se revela como persona, es decir, que es soporte de una vida espiritual y libre, sostiene Stein. Verdaderamente, si bien históricamente 'persona' era un término que se utilizaba en el teatro griego para designar las máscaras utilizadas por los actores, fue resignificado a la 
luz del dogma trinitario comenzando a designar a un ser perfecto y espiritual. El ser espiritual, dice Stein, no es solo el que no ocupa un lugar en el espacio y es inmaterial, sino el ser que posee una vida interna y sale fuera de sí sin perderse a sí mismo. Así, el ser personal posee una apertura interna, es decir, es consciente de sí mismo y de su vida, y una apertura externa, está situado en un mundo penetrado de sentido y volcado intencionalmente hacia él. La persona es a su vez un ser libre, tiene la capacidad de configurarse a sí misma y no está sujeto a los bienes que se le presentan.

En la segunda sección, presenté cómo se da la imagen del Dios Trino en la creación. Para Edith Stein, entre Dios y sus creaturas está latente una doble inclinación, por un lado un abismo, una distancia infinita entre el ser divino y eterno y el ser finito y creado, por el otro, una auténtica relación a modo de imagen entre Dios y su creación. En efecto, para Stein toda la creación, tanto los seres racionales como los irracionales, han sido creados a imagen del Dios trinitario, todo ser finito participa del ser eterno, en cuanto que lo tiene como arquetipo de su ser, está hecho a imagen del ser divino, que es esencialmente trinitario. Este despliegue trinitario del ser se encuentra en toda la creación, desde el ser meramente material a los seres angélicos pasando por los seres humanos. Es decir, todo ser finito puede entenderse en clave trinitaria. En cuanto son seres independientes y subsistentes, los seres finitos son imagen del Padre; en cuanto poseen una esencia y un sentido, son imagen del Hijo, el Verbo; en cuanto que se desarrollan según su esencia, poseen una fuerza o están vivos, son imagen del Espíritu Santo.

Finalmente, presenté cómo se da la imagen del Dios trinitario en la persona humana y por ende cómo esta noción es resignificada y enriquecida. Para Stein somos personas porque Dios, que es una persona Él mismo, nos creó a su misma imagen. Dado que el Dios cristiano es un Dios Trino, esta imago Trinitatis se refleja en las personas humanas tanto en la tri-partición de su naturaleza (cuerpo-alma-espíritu) y en lo que es más auténticamente una imagen de Dios, esto es, su alma espiritual. En efecto, para Stein, en cuanto que el hombre ha sido creado a imagen del Dios Trino, posee una naturaleza tripartita de cuerpo, alma y espíritu: por su cuerpo, es imagen del Verbo Encarnado, porque su cuerpo y alma forman un ser subsistente, son una imagen del Padre, por poseer un alma espiritual, es imagen del Espíritu Santo. Ahora bien, tanto el alma como el espíritu considerados en sí mismos también pueden ser considerados una imagen del Dios Trino. De este modo, toda la naturaleza humana, todo lo que el hombre es, puede entenderse a la luz del Dios trinitario.

En conclusión, el pensamiento de Edith Stein vuelve a llenar de contenido ontológico la noción misma de Trinidad, que recupera su carácter performativo intrínseco al volver a ser principio de interpretación de la 
realidad, trayendo nuevos niveles de comprensión del ser finito con consecuencias antropológicas relevantes. En efecto, analizar la naturaleza del Dios trinitario permitió llegar a una comprensión más profunda del ser creado, y específicamente de la persona humana. Stein profundiza, resignifica y da el fundamento último del ser personal al analizar la imagen de la Trinidad en la persona humana. De este modo, el pensamiento de Edith Stein se presenta como sumamente relevante si se quiere hacer frente a la noche oscura en la que se han sumergido la filosofía y la teología.

\section{REFERENCIAS}

Ales Bello, A. (2008). Edmund Husserl and Edith Stein: The Question of the Human Subject. American Catholic Philosophical Quarterly, 82(1), 143-159.

Baseheart, M. C. (1987). Edith Stein's Philosophy of Person. Carmelite Studies, (4), 34-49.

Borden, S. (2003). Edith Stein. Londres: Continuum.

Calcagno, A. (2007). The Philosophy of Edith Stein. Pittsburgh, Pa.: Duquesne University Press.

Coda, P. (2018). Para una ontología trinitaria. Si la forma es relación. Ciudad Autónoma de Buenos Aires: Ágape.

San Agustín. (1948). De Trinitate. En Obras de San Agustín (Tomo V). Madrid: BAC.

Santo Tomás de Aquino. (2000). Summa Theologiae. En Corpus Thomisticum (E. Alarcón, Ed.). Pamplona: UNAV. Disponible en http://www.corpusthomisticum.org/sth0000.html.

Stein, E. (2007a). La estructura de la persona bumana. (J. Mardomingo, Trad.) Madrid: BAC.

Stein, E. (2007b). Ser finito y ser eterno. Ensayo de una ascensión al sentido del ser. En Obras Completas. Vol. III: Escritos Filosóficos (etapa de pensamiento cristiano: 1921-1936). (A. Pérez, J. Mardomingo y C. Ruiz Garrido, Trads.) Burgos: Monte Carmelo.

Von Balthasar, H. (1986). On the concept of person. Communio, (13), 18-26.

Sumario: Introducción; 1 . Un Dios Trino y personal: clave interpretativa del ser real finito, 2. La imagen del Dios Trino en la creación; 3. La imagen de la Trinidad en el hombre; Conclusión; Referencias. 